\title{
ADIÓS A HOURCADE
}

GOODBYE TO HOURCADE

\section{PATRICE VERMEREN ·}

Profesor Emérito de la Université París VIII Vincennes-

Saint Denis (Francia).

\section{Registro bibliográfico}

VERMEREN, PATRICE «Adiós a Hourcade», en: ESTUDIOS SOCIALES, revista universitaria semestral, año XXX, $n^{\circ} 58$, Santa Fe, Argentina, Universidad Nacional del Litoral, enero-junio, 2020, pp. 197-203.

\section{Descriptores · Describers}

Eduardo Hourcade / historia / amistad

Eduardo Hourcade / history / friendship

Podría haber escrito, como cualquiera podría haberlo hecho, a propósito de un amigo: «desde hace mucho tiempo, temía tener que decir adiós a Hourcade». No, porque tratándose de Eduardo, la palabra habría evocado un «a-Dios», sino porque temía que para él — para hablar como Levinas—, la muerte no se interpretara como un pasaje a otra existencia, que se prolongaría en un nuevo decorado, sino como un pasaje a la nada. Identificar la muerte con la nada, es lo que querría hacer el asesino, según Levinas, releído por Derrida; pero esa nada se presenta como si poseyera la estructura de una imposibilidad, de una prohibición: el rostro del otro me prohíbe matar. En pleno shock por la terrible noticia de la muerte de Eduardo, escribí esta nota y se la envié a nuestros amigos de Rosario:

«Mi amigo Eduardo Hourcade murió. Durante su última estadía de investigación en la EHEss, en París, nos vimos muy a menudo. Eduardo había comenzado su estadía dando una conferencia en el seminario Diálogos filosóficos en la Maison de l'Amérique Latine, sobre «Ciencia y Filosofía: Pensar América desde Francia, en el siglo XVIII. En las líneas que Eduardo había redactado como presentación, es muy fácil reconocer la idea matriz que ordenaba sus trabajos: ‘Aunque abierta a todos los dominios del conocimiento, la Ilustración en Francia pecó por falta la curiosidad respecto del mundo extra-europeo, lo que tuvo repercusiones sobre el nivel de conocimiento de esos espacios periféricos. Los relatos y las investigaciones en torno de la quatrième partie du monde (América) suscitaron infinitamente menos interés que las noticias 
provenientes del Imperio Turco o que los relatos del peregrinaje a Tierra Santa. Por ello, el estudio de América, como tema de la ciencia y de la filosofía, se hizo ineludible. Nos detendremos en la manera en la que la geografía — llamada científica — de Buffon consideró a América, como en el modo en el que la filosofía de la Ilustración tomó en cuenta a los indígenas americanos, que le eran contemporáneos. Sobre ese punto, nos interesaremos por el texto sobre los salvajes del abad Raynal, corregido por Diderot. Doctor en Historia y Civilización de la Escuela de Altos Estudios en Ciencias Sociales (EHESS) y licenciado en Historia por la Universidad de Buenos y de Costa Rica, Eduardo eligió ser profesor en la Universidad Nacional de Rosario e investigador del CONICET, con sede en la Universidad de San Martín (Buenos Aires). Entre 2007 y 2013, fue director de la Escuela de Doctorado de la Facultad de Filosofía de la Universidad de Rosario. Varias veces me invitó a dictar seminarios — sobre Canguilhem, el error, el concepto y la vida, y sobre las lecturas franceses de Nietzsche-; también dirigimos juntos la bella tesis doctoral de Mercedes Betria: Pensar la politica: la generación de I837 y la institución del orden político moderno. 1830-1853: la mirada de Echeverría y de Alberdi. Eduardo era muy exigente, tanto en el trabajo intelectual como en la amistad. Poseía, además, un vínculo con el mundo, penetrado por una ironía que se adivinaba radical y desesperada, pero que sabía traducir en una sonrisa benevolente, como si la exigencia intelectual o afectiva que lo habitaba no pudiera cambiar el orden de este mundo. Así, adaptaba sus deseos al mundo y encontraba allí el placer de compartir - en un seminario o alrededor de una buena mesa - el arte de conversar entre amigos. Recuerdo varias encantadoras noches al borde del Paraná con nuestros amigos de Rosario; también recuerdo que, antes de su partida de París —el 24 de junio-, cenamos agradablemente por última vez: me invitó al restaurant L'Aveyronnais. Allí, hablamos largamente acerca de los desafíos actuales y de la publicación en francés de su bella tesis de doctorado, cuyo jurado había integrado.

Los argentinos perdieron un historiador de talento; los franceses, al mejor especialista de las miradas francesas sobre el Río de La Plata; yo, un amigo, indisociablemente ligado, en mi memoria, a esta parte considerable de mi vida que está en Rosario. Que su mujer, Cecilia Lesgart, su hija, Hugo Quiroga y todos los amigos que teníamos en común, reciban mis entristecidas condolencias».

Buscando en mi memoria y en mis archivos, recuerdo que Eduardo me había propuesto formar parte del jurado de su tesis doctoral en la Escuela de Altos Estudios en Ciencias Sociales (EHEss) junto con su director de tesis, Roger Chartier, 
y Jacques Revel, Yves Saint-Geours y François Hartog. El jurado elogió su texto - muy por encima de lo exigido habitualmente— y la metodología que utiliza; y ello, por supuesto, vinculado con la materia, o más bien las materias, que Eduardo Hourcade interrogaba. Esta defensa de tesis, que tuvo lugar el 3 de julio de 2003, en el 54 del Boulevard Raspail, fue, para Eduardo, una escena privilegiada, es decir, un lugar en el que se discuten conceptos todavía en construcción, a la espera de lo que puede aparecer sin que ello implique una verdad oculta detrás de la apariencia, «en la que todo se juega en la presentación de lo que apareces. Cada uno jugó su rol: Hartog, se preguntó ‘¿qué era ser argentino?); Chartier, evocó las bibliotecas argentinas; Revel, subrayó la composición de tipo rapsódico de la tesis y se interrogó sobre la existencia del Río de la Plata; Saint-Geours, resituó los desafíos del período histórico considerado. Mi lugar era algo diferente: estaba allí, por cierto, como filósofo pero, también, por haber frecuentado los archivos del siglo xIx de ambos lados del Atlántico; y, también, como su amigo. Eduardo me había convocado para continuar las conversaciones que habíamos tenido desde siempre, especialmente en Rosario, en los restaurants de pescadores al borde del Paraná en compañía de Silvana Carozzi, Hugo Quiroga y Susana Villavicencio. El estilo académico de mi intervención, si se presta atención, para nada oculta la continuidad con el diálogo que, desde hacía mucho tiempo, se había instalado entre nosotros y que perduraría hasta su muerte. Releo el informe de defensa que redacté en su momento:

«Patrice Veremen, profesor de filosofía, toma la palabra. Recuerda que, en su preinforme, subrayó que, al estudiar la construcción cultural de una sociedad nueva, el Río de la Plata y su relación con Francia y Europa en el período I800-1850, Eduardo Hourcade se dio como objeto de investigación describir en extensión y en comprensión la «esfera cultural〉 (expresión que toma de Habermas pero de un Habermas releído por Roger Chartier), o, si se quiere, sobre los personajes conceptuales (cfr. Gilles Deleuze) que están en la base de la identidad nacional naciente de los cuatro Estados que reemplazaron el Virreinato español del Río de la Plata: Argentina, Bolivia, Paraguay y Uruguay. Más específicamente, trata de interrogar los caminos específicos que tomaron los intelectuales de la Argentina para pensar su emancipación política a partir de las nociones heredades de Rousseau y de los actores y comentadores de la Revolución Francesa, y del modo en que desplazaron la experiencia post-revolucionaria, naturalizándola en América del Sur. De lo que se trata, pues, es de la naturaleza, la estructura y la función de ese desplazamiento. Desplazamiento de la percepción 
del Otro, si ello es posible, que es ser percibido como diferente; desplazamiento de la representación del Mismo, en la medida en que hay una modificación, a su vez, de la representación por parte de la revolución argentina, de la experiencia francesa de I789, a partir de haber re-atrapado el credo revolucionario de libertad y de igualdad. Desplazamiento, en fin, y éste es un punto decisivo del sistema material de ideas políticas de la generación del ' 37 — o si se quiere de ese dispositivo de apropiación-, de los clivajes y de las alianzas entre nociones en la escena agonística que une, indisociablemente, lo intelectual y lo político.

"Con astucia, Eduardo Hourcade muestra que, antes que nada, existe una mirada sobre la mirada del otro, una puesta en duda del juicio de la Ilustración europea acerca de la inferioridad del mundo americanor propuesta por los naturalistas. Muestra, también, cómo la joven generación busca adquirir su autonomía vis-à-vis de las políticas para preocuparse mejor de la política. Como buen historiador, Eduardo Hourcade reconstituye, primero, las condiciones de emergencia de las ideas y de las instituciones nuevas, en la retrospección de las instituciones del período colonial, que habían entrado en crisis. Objeta, entonces, las interpretaciones tradicionales, como la de José Ingenieros, que veía en el período colonial una analogía con la Edad Media. Por otro lado, toma y desarrolla un interesante ejemplo, el de los debates filosóficos (p. I43/I49). La cuestión que le preocupa allí es la de las formas de transmisión con la finalidad de extender el público de destinatarios, más que una mutación de los contenidos de los saberes, referidos tanto a Suarez como a Santo Tomás. Y, obvio, puede decirse que el impacto de las nuevas ideas de la Enciclopedia y de Voltaire no poseen el mismo sentido que en la otra orilla del Atlántico, y que esas ideas pueden codearse con las de Bossuet: «el espíritu filosófico de la Ilustración no es, en la América Hispánica, ni escéptico ni antirreligioso (p. I50)). Pero, al mismo tiempo, puede afirmar que «los proyectos sucesivos de reforma de la enseñanza, a partir de i8ıo, no hacen más que retomar los argumentos y puntos de vistas expuestos mucho tiempo antes` y que «la ruptura reivindicada, luego, por los jóvenes revolucionarios se hizo a posteriori. Esa fue la primera pregunta que P. Vermeren le planteó a Hourcade. Es preciso, sin embargo, reconocer que aquí, como en el resto del trabajo, las fuentes que el candidato utiliza para desplegar su punto de vista son completamente originales y que el corpus utilizado es exhaustivo en cuanto a las obras publicadas.

«Eduardo Hourcade se dedica, entonces, a desentrañar y trabajar las referencias francesas, en la medida en que fueron constitutivas de las ideas argentinas de la generación romántica y, especialmente, en Echeverría, Sarmiento y Alberdi. Para quienes 
conocen los estudios clásicos de José Ingenieros a Félix Weinberg o a Jorge Dotti, es evidente que, en esta parte, Eduardo Hourcade manifiesta la notable originalidad y la fecundidad de su método, así como la singularidad de su trabajo. Elige, también, trabajar sobre otros textos, en particular, sobre artículos de prensa e, incluso, una pieza de teatro, poco leídos y citados, en los cuales se elabora el pensamiento más próximo a la actualidad política y a los combates por el reconocimiento identitario. De este modo, resalta fuentes poco trabajadas y lecturas inadvertidas: las referencias a la Encyclopédie Nouvelle, a la Revue Encyclopèdique y a De l'Humanité de Pierre Leroux, en los artículos escritos por Echeverría para el periódico El Conservador de Montevideo, en julio de I848, entre otras. La segunda pregunta que se le plantea al candidato remite a la naturaleza específica de esas referencias al pensamiento francés, a los efectos del desfasaje y de amalgama (como, por ejemplo, las conexiones entre Cousin, Jouffroy, Leroux, Damiron y Lerminier), a las modalidades de apropiación y de naturalización de los conceptos y temas (así como existe la invocación de figuras de la Antigüedad clásica, como Licurgo, legislador de Esparta, que es preciso interrogar la manera en que esa invocación moviliza los Antiguos para legitimar la modernidad de una tradición reconstruida).

«Hourcade muestra también con pertinencia cómo la elaboración simbólica de Argentina, incluso tomando en consideración Río o los Andes, se centra principalmente en la pampa, desde Argirópolis de Sarmiento a La Cautiva de Echeverría. Y cómo se pasa desde el espacio al tiempo y a la constitución de una historia nacional, cuyo origen puede ser real o mítico, cuya ortodoxia está definida por la exclusión de lo que no es ella misma y cuyo presente no está en la repetición de sí misma, sino en la invención de la nueva Argentina y del un ser argentino. La tercera pregunta que se le hace al candidato apunta las condiciones de posibilidad de un paradigma político de la cultura argentina y a la especificidad de esos intelectuales del Río de la Plata».

Mis notas conservan el trazo de otras preguntas que le planteé, relativas a los temas que había trabajado: la invocación de las figuras de la Antigüedad en El Censor, más allá de Esparta y de Licurgo; la tipología de los viajes (en relación con David Viñas); los presupuestos de la puesta en escena del Indio: debilidad, duplicidad y cobardía moral, ignorancia intelectual, suciedad corporal, que tenían como finalidad reducirlo a la animalidad, para excluirlo mejor del pueblo republicano (ver Amédée Jacques); la supuesta ubris de la naturaleza americana (Charles de Mazade); las lecturas franceses de la joven generación argentina 
(Cousin, Villemainm, Quinet, Michelet, Janin, Mérimée, Nisard —ver Vicente López-y también Jouffroy y Leroux); las promesas de un futuro y de una libertad crítica de los sabios y la metafísica del pueblo en Alberdi, el pueblo inadecuado a su concepto y la República argentina, que no había encontrado aún su país real, como también la dimensión utópica de los pensadores franceses de la Monarquía de Julio; la crítica del sensualismo y de los idéologues y el destino singular del espiritualismo en el Río de la Plata (según Arturo Andrés Roig); la especificidad de esos intelectuales argentinos, tal como Eduardo construye su personaje conceptual.

Estas cuestiones animaron nuestros diálogos en todas las ocasiones que pudimos, incluso incorporando otros interlocutores: por ejemplo, a propósito de la tesis de Mercedes Betria, que dirigimos en co-tutela entre la Universidad Nacional de Rosario y la Universidad de París viII. En esa ocasión, habíamos modificado nuestras posiciones relativas puesto que él ya no era el tesista, sino el director de tesis. Sin embargo, Eduardo no había cambiado su régimen de discurso: mantenía el diálogo que presupone la igualdad en el intercambio inacabable y perpetuo de saberes y argumentos. En realidad, consideraba las actitudes académicas como ridículas, porque, para él, afectaban la autenticidad de la investigación universitaria, que buscaba que fuera sin condiciones. En ese sentido, del lado de Saint-Just (y de Deleuze y Abensour): estaba en favor de las instituciones como sistemas organizados de medio, de modelos positivos de acción, generadoras de libertad y contra las leyes que limitan la libertad y engendran la servidumbre. Mercedes Betria, que escribió una tesis excelente sobre Pensar la politica: la generación de I837 y la institución del orden político moderno 1830-1853. Las miradas de Echeverría y Alberdi, nos sorprendió por la singularidad de su investigación, que esclareció con una mirada novedosa la filosofía de Alberdi tomada de Théodore Jouffroy y que exploró los archivos olvidados de Albert Stäpfer, un joven romántico liberal adepto al carbonarismo y traductor de Goethe al francés, para comprender los efectos de su amistad con Echeverría en ocasión de su estadía de cuatro años en París. La defensa de tesis, cuyo jurado estuvo constituido por Gabriela Rodríguez, Pilar González Bernaldo de Quirós, Beatriz Dávilo et Georges Navet, puso a prueba el diálogo que los tres habíamos mantenido durante muchos años. Nunca vi más feliz a Eduardo que en ese momento, en el que se superponían los cuatro ejes de análisis que constituían, según la candidata, la sub-estructura del discurso de la Generación del 37, constitutivo del exilio insurreccional de los opositores a Rosas: la consciencia histórica colectiva generacional; el lugar de la escritura 
como modo de gestión del espacio público moderno; el paradigma capacitario de la política como episteme estructurante de los conceptos y los lenguajes de su discurso político y la Representación como principio racional que dinamizaba el orden político moderno. Para Eduardo, era una escena privilegiada, quizás —o por ello mismo- agonística, de reencuentro entre historiadores y filósofos, de confrontación de la historia conceptual y de la filosofía política, en relación con las preguntas formuladas por Mercedes Betria: ¿cómo se piensa el orden político cuando el Estado nacional es una entidad todavía inexistente? ¿Cómo se pensó la política entre 1830 y 1853? Estas preguntas no eran más que una variación de su propia pregunta: ¿qué es ser argentino? y de la nuestra, la que compartía con su propia generación de historiadores como con mi propia generación filosófica: ¿cómo pensar la política?

La muerte pudo haber interrumpido nuestra amistad. Pero el diálogo continúa con su obra, por cierto inacabada, pero que es urgente publicar ya que nadie todavía nadie la exploró en todas sus dimensiones. Decir Adiós a Hourcade es también desearle la bienvenida, a la manera de Levinas que cita Derrida — sé que esto le podría haber resultado un tanto ridículo, ya que poseía el humor feroz y la ironía filosófica, pero habría recibido el mensaje con un oído malicioso y con una sonrisa de historiador divertido- : «El decir a-Dios cruza en una palabra, pero hasta el infinito, la salvación y la promesa, la bienvenida y la separación: la bienvenida al corazón de la separación, la santa separación. En el momento de la muerte pero también en el encuentro del otro en ese mismo momento, en el gesto de acogida y siempre al infinito: Adiós». 